\title{
Endoscopic removal of a fractured esophageal stent from the mediastinum and leak closure with endoscopic vacuum therapy
}

Self-expanding metal stents (SEMSs) are effective and safe for the treatment of esophageal leaks [1, 2]. However, optimal timing of stent removal is vital, as hyperplasia of the tissue can make it challenging $[3,4]$. Complications range from bleeding and stent overgrowth requiring multiple endoscopic procedures to perforation requiring surgical repair [5].

We present the case of a 36-year-old woman with an esophageal perforation due to partial stent dislocation of a SEMS into the mediastinum. The dislocation occurred during an endoscopic extraction procedure at another hospital 35 days after implantation ( - Fig. 2, Video 1).

The patient was transferred to our hospital, and we performed a flexible endoscopy (GIF-HQ190; Olympus, Tokyo, Japan) during which we discovered a partially broken SEMS (Hanarostent; Olympus Europa, Hamburg, Germany) that had moved into the mediastinum. Equipped with a forceps (MTW Endoskopie Manufaktur, Wesel, Germany), we tried to pull the SEMS into the esophagus but did not succeed because of a remaining embedded lower flare end. We then used an endoscopic knife (HookKnife, Olympus Europa) to cut the remaining nitinol filaments out of the tissue in the distal area of the stent. Then, we used a forceps to elevate the lower flare end circumferentially until it was freed from the mucosa. Finally, we removed the SEMS completely.

The final screening showed a 3-cm esophageal perforation with a view into the mediastinum. Endoscopic vacuum therapy was performed, and all tailored sponges (Eso-SPONGE; Aesculap AG, Tuttlingen, Germany) were placed intraluminally in the esophagus. All four consecutive endoscopies conducted to exchange the sponge system showed a remarkable healing process. In the final endoscopy (13th post-interventional day), the leak

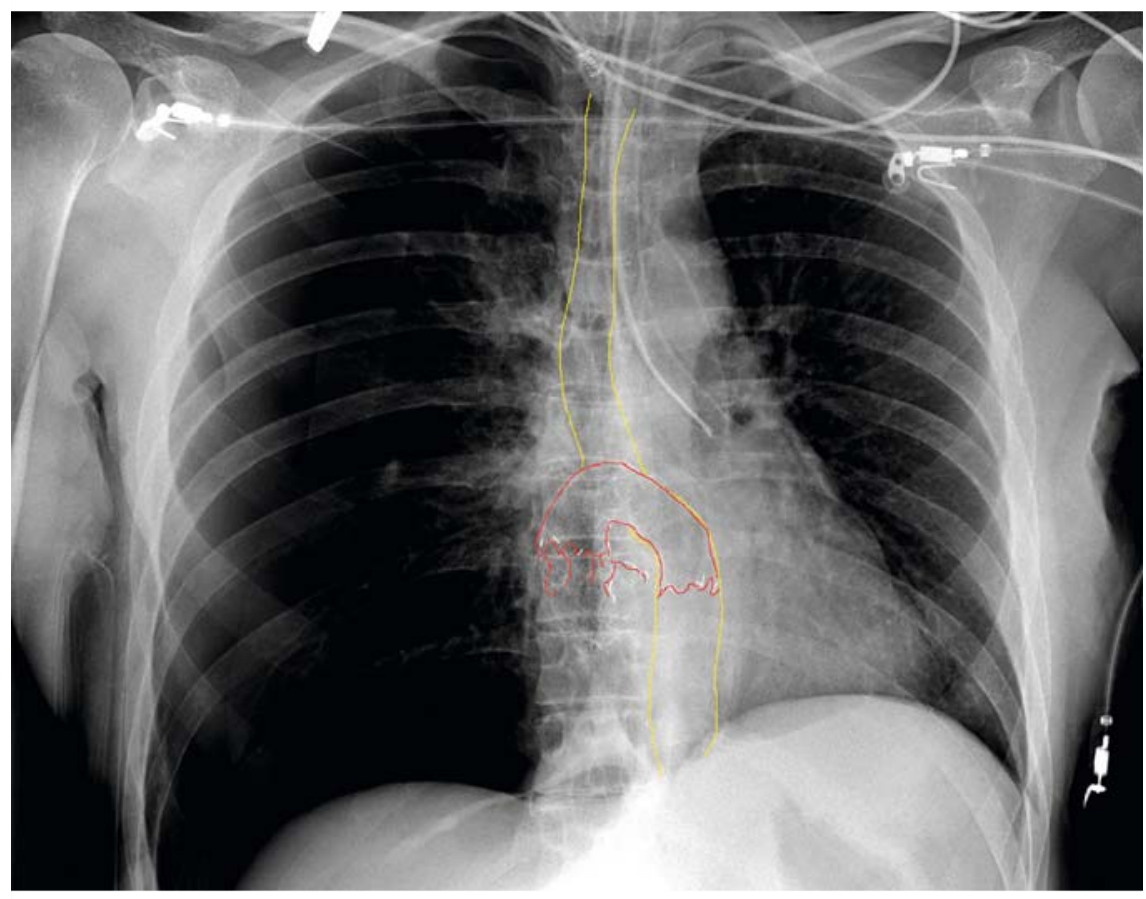

Fig. 1 Stent dislocation after unsuccessful removal (red: stent; yellow line: course of the esophagus).

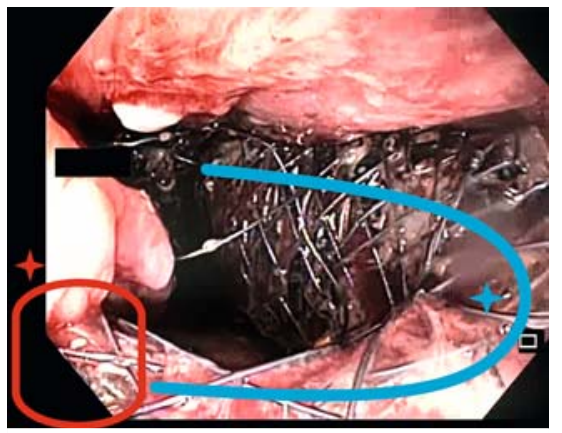

Fig. 2 View into the mediastinum: esophageal perforation (red star) and broken stent (blue star) in the mediastinum (blue line: direction of the stent).

was sealed with a small and encapsulated cavity (\$Fig.3). Endoscopic vacuum therapy was terminated, and a computed tomography (CT) scan of the chest confirmed the improvement. An aspergillus pneumonia delayed hospital discharge.

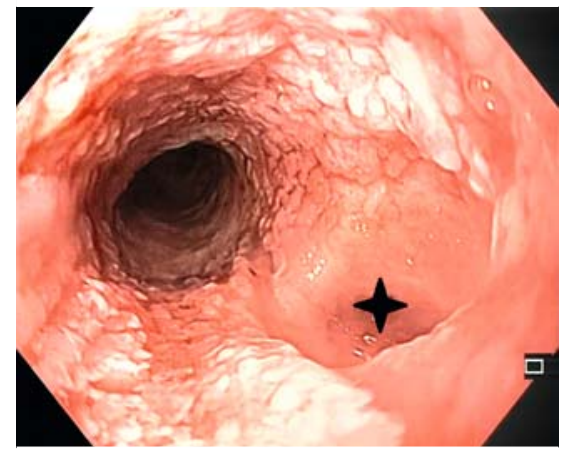

- Fig. 3 Sealed esophageal leak with a small clean cavity (black star).

On the 24th post-interventional day, the patient was discharged without any remaining pathology.

Endoscopy_UCTN_Code_TTT_1AO_2AZ 


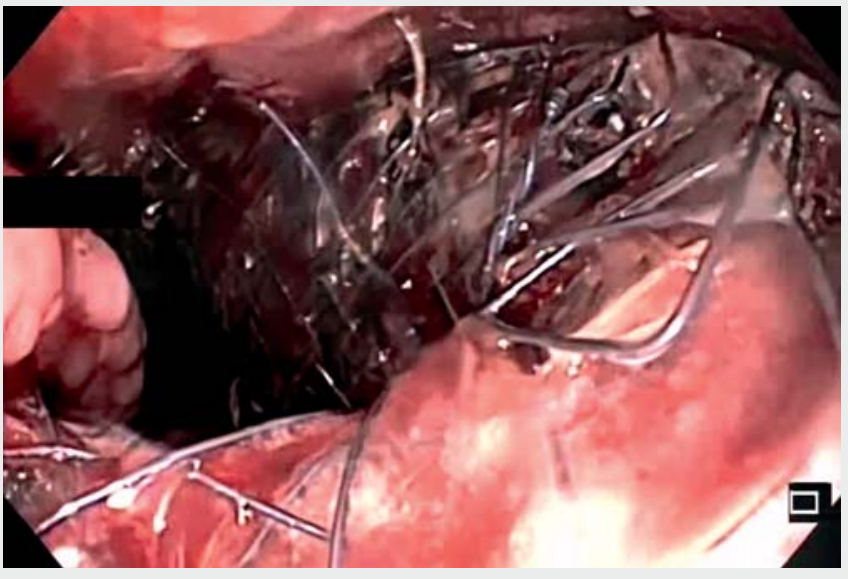

Video 1 Endoscopic removal of a fractured esophageal stent from the mediastinum and leak closure with endoscopic vacuum therapy.

\section{Competing interests}

The authors declare that they have no conflict of interest.

The authors

Seung-Hun Chon ${ }^{1}$, Eleonora Ramadori ${ }^{2}$, Daniel Pinto dos Santos ${ }^{3}$, Florian Lorenz ${ }^{2}$, Hakan Alakus ${ }^{2}$, Tobias Goeser ${ }^{2}$, Christiane Josephine Bruns ${ }^{1}$

1 Department of General, Visceral, Cancer and Transplantation Surgery, University Hospital of Cologne, Germany

2 Department of Gastroenterology and Hepatology, University Hospital of Cologne, Germany

3 Department of Radiology, University Hospital of Cologne, Germany

\section{Corresponding author}

\section{Seung-Hun Chon, MD}

Department of General, Visceral, Cancer and Transplantation Surgery, University Hospital of Cologne, Kerpener Str. 62 , 50937 Cologne, Germany Fax: +49-221-478-86227

seung-hun.chon@uk-koeln.de

\section{References}

[1] Spaander MC, Baron TH, Siersema PD et al. Esophageal stenting for benign and malignant disease: European Society of Gastrointestinal Endoscopy (ESGE) Clinical Guideline. Endoscopy 2016; 48: 939-948

[2] Dasari BV, Neely D, Kennedy A et al. The role of esophageal stents in the management of esophageal anastomotic leaks and benign esophageal perforations. Ann Surg 2014; 259: $852-860$
[3] Freeman RK, Ascioti A], Dake M et al. An assessment of the optimal time for removal of esophageal stents used in the treatment of an esophageal anastomotic leak or perforation. Ann Thorac Surg 2015; 100: $422-$ 428

[4] Sharma P, Kozarek R. Role of esophageal stents in benign and malignant diseases. Am J Gastroenterol 2010; 105: 258-273

[5] Hirdes MMC, Vleggaar FP, Van der Linde K et al. Esophageal perforation due to removal of partially covered self-expanding metal stents placed for a benign perforation or leak. Endoscopy 2011; 43: 156-159

Bibliography

Endoscopy 2022; 54: 334-335

DOI 10.1055/a-1388-6058

ISSN 0013-726X

published online 15.3.2021

(c) 2021. Thieme. All rights reserved.

Georg Thieme Verlag KG, Rüdigerstraße 14,

70469 Stuttgart, Germany

\section{ENDOSCOPY E-VIDEOS}

https://eref.thieme.de/e-videos

回屌 Endoscopy E-Videos is an open access online section, 自嗮: reporting on interesting cases and new techniques in gastroenterological endoscopy. All papers include a high quality video and all contributions are freely accessible online. Processing charges apply (currently EUR 375), discounts and wavers acc. to HINARI are available.

This section has its own submission website at https://mc.manuscriptcentral.com/e-videos 